\title{
Entrevista
}

\section{Maria Helena Lopes: Relações com a Metodologia de Jacques Lecoq}

\section{Cláudia Müller Sachs*}

\section{Resumo}

A entrevista aborda a influência da metodologia de Jacques Lecoq nos processos criativos da diretora. Ela relata aspectos de sua trajetória artística e de sua maneira de trabalhar com os atores a partir de práticas corporais e de improvisações, falando sobre seu trabalho de criação e de construção dramatúrgica relacionados ao conhecimento e experiência adquiridos naquela escola. A entrevista foi realizada em 2002 como material para a dissertação de mestrado intitulada "A metodologia de Jacques Lecoq: estudo conceitual".

Palvras-chave: direção; formação; Jacques Lecoq; improvisação; ator

\begin{abstract}
The interview addresses the influence of the methodology of Jacques Lecoq in the creative processes of this director. She reveals aspects of her artistic trajectory and her way of working with actors from bodily practices and improvisations, talking about creation and dramaturgy related to the knowledge and experience acquired in that school. The interview was done for the dissertation of master entitled "The methodology o Jacques Lecoq: a conceptual study".
\end{abstract}

Key-words: direction; formation; Jacques Lecoq; improvisation; actor. 
Maria Helena Lopes, diretora, nascida em Pelotas-RS, iniciou sua carreira como bailarina. Lecionou as disciplinas de expressão corporal, improvisação, interpretação e direção no Instituto de Artes, no Departamento de Artes Dramáticas, na Universidade Federal do Rio Grande do Sul - UFRGS. Cursou a escola de Lecoq, em Paris, de 1978 a 1980 . Dirigiu vários espetáculos em Porto Alegre e de volta ao Brasil, em 1981, criou o grupo Tear, importante referência para o teatro de criação gaúcho, destacando os espetáculos "Reis Vagabundos", "Crônica de uma cidade pequena", "O império da cobiça", entre outros, pelos quais recebeu inúmeros prêmios. Em 1995, dirigiu o elogiado espetáculo "Impressões Transitórias" no Rio de Janeiro. Atualmente reside em Porto Alegre e trabalha com oficinas e outros projetos de criação.

Cena: Quanto a sua formação: O que levou você a fazer a escola de Lecoq? Quando você cursou? $O$ que você buscava? $O$ que encontrou? 0 que mais chamou sua atenção na pedagogia e visão de teatro de Lecoq? $O$ que mudou na sua concepção de teatro a partir desta experiência? 0 que caracteriza o seu teatro depois de Lecoq?

Maria Helena: Bem, em 1977 fiz um daqueles cursos compactos com Lecoq. Foi ali que tomei conhecimento, quer dizer, conhecer essa abordagem eu já conhecia há muito tempo, pois Eugênio Kusnet, que foi meu mestre stanislavskiano maravilhoso, havia me recomendado. Ele me disse "é o que você está buscando". Eu já gostava de trabalhar com a improvisação, com a via do movimento no trabalho do ator começando pelo corpo, que eu considerava fundamental. Outras pessoas, na época, também começaram a me aconselhar. Isto nos anos 1970, que é quando eu comecei a dirigir. Iniciei como atriz substituta, fazendo uma ou duas experiências, mas não era o meu chão, eu me aborrecia. Eu fiz, então, uma série de direções no "Província", que era um grupo que surgiu nos anos 1970 com o pessoal que trabalhava junto no DAD. Já naqueles trabalhos eu buscava a via da improvisação. Mesmo trabalhando com um texto, dirigindo um Harold Pinter, um roteiro de Bertold Brecht, etc., eu invariavelmente buscava o caminho da improvisação, porque me parecia que o método característico de mesa, de decorar, etc., terminava por cristalizar... Eu achava que ficava tudo duro, muito rígido. Sentia aquela dificuldade, com a qual eu não sabia como lidar. Eu achava extremamente enfadonho o método tradicional, achava aquilo tudo morto, não funcionava. Eu lia muito, me informava, e buscava um trabalho corporal, muito simples no início, para os meus atores.

\section{Cena: E nessa época você lecionava teatro também?}

Maria Helena: Eu dava aulas de dança. Trabalhava como aluna-mestra com minha professora de dança clássica, Lya Bastian Meyer, e com ela também aprendi a dirigir. Eu também fazia aulas de dança moderna em Montevidéu e já sabia que o caminho era aquele, o moderno. $\mathrm{E}$, lá, eu fazia um trabalho que visava um outro aspecto do movimento, que era a expressão corporal. Bem na época da expressão corporal, fim dos anos 1960, 1970 em diante. Aqui em Porto Alegre, fui convidada a trabalhar com os atores, foi quando me senti mesmo dentro do teatro. Então, no trabalho corporal com os atores, via expressão corporal, já tinha um caminho que levava para uma pesquisa de movimento expressivo. Depois, entrei na UFRGS e, através do trabalho com expressão corporal, encontrei Luiz Arthur Nunes, que me convidou para fazer coreografias para cena. Fiz um trabalho de movimentação de coro para algumas montagens; foi muito intuitivo, eu não tinha ainda a técnica, como depois adquiri na Escola de Lecoq. Bem, eu entrei na faculdade e fiz uma direção quase que de cara, e deu muito certo! Ou seja, então, "talhada para a direção"(risos). Eu me imbuí da condição de diretora e quis continuar: gostei, 
amei, e aí me atrevi a trabalhar um texto do García Lorca. Após, fiz um trabalho de máscaras, que era uma ópera bufa renascentista, que também deu muito certo. Nesse ínterim, tornei-me pupila de Eugênio Kusnet, pois comecei a ir para São Paulo para estudar Stanislavski com ele. Foi maravilhoso. Ao mesmo tempo, eu busquei um outro tipo de teatro, ou seja, toda esta via de Stanislavski, de teatro de texto - que era como eu compreendia na época - me interessava muito, mas me interessava ainda mais um outro tipo de teatro. Então comecei a batalhar para ir para Paris. Finalmente, em 1978, fui para Paris fazer a escola de Jacques Lecoq. Descobri, lá, o que eu precisava, ou seja, as ferramentas para trabalhar o processo criativo do jeito que eu queria. Antes eu tinha entraves para lidar com a questão dramatúrgica, ou seja, por onde, na improvisação, eu deveria caminhar até a dramaturgia, até a criação de uma dramaturgia. Como complemento dessa abordagem, fiz o curso "Da improvisação ao texto" com Serge Martin. Eu queria criar a minha própria dramaturgia. O primeiro ano na escola de Lecoq foi, para mim, fundamental. Ele me deu régua e compasso para formar esse ator que eu preciso. Esse ator que vai me dar esse material com que eu vou compor a minha dramaturgia, que passa normalmente pelo ator. Quer dizer, esse é o caminho. Na escola, o que é fundamental, o que eu aprendi, é a pedagogia da responsabilidade: você tem que cumprir a sua parte, não tem nada mastigado. É uma exigência e um rigor absoluto. Você tem que estar numa permanente descoberta das suas possibilidades, das suas potencialidades, isso para mim foi a primeira coisa. Quando voltei de lá, estava pronta para fazer o trabalho que eu queria fazer, que era os catadores de lixo. Essa coisa maravilhosa da pedagogia de Lecoq "[...] vai para a rua para aprender a vida, como é que se vive, suas pulsações, como é que as coisas acontecem". Isso eu acho de um valor incalculável! E a outra coisa que eu ouvia muito na escola dele era "[...] se é mais interessante na rua, não vale a pena fazer no teatro". Então quando eu voltei, tinha certeza de que eu não poderia fazer o que eu via na rua - os catadores de lixo - aquela realidade eu não poderia reproduzir na cena, realisticamente. E também não era sobre o vagabundo em si, sobre o catador em si, mas sobre o outro lado da sociedade de consumo, o dejeto, a coisa que é jogada fora. E então é uma parábola, é criar, por outra via, é falar do assunto... Deu muito certo, por isso, acho eu, foi por isso que escolhi os clowns. Eu levei muito tempo trabalhando os clowns, antes de me atrever a fazer clown, por exemplo. $E$ isso tem acontecido sempre: enquanto eu não incorporo, não torno meus esses conhecimentos, eu não posso mexer com eles. Nem posso transmitir, nem posso gerar criação com eles. Desse modo, é preciso introjetar profundamente esses conhecimentos, torná-los meus e, assim, eu tenho a liberdade para usá-los, já transformados, evidentemente. Quando a coisa se torna tua, já tem uma transformação. Mas a raiz, a base está lá, nesse conhecimento que adquiri na Escola de Lecoq. A partir da Escola, minha vida se transformou, eu me organizei e adquiri confiança, porque, então, sabia por onde caminhar. Pois antes eu "tapeava"(risos), porque conhecia vários elementos de movimento, muitas coisas. Eu acho que eu tenho o privilégio de ter vindo da dança, por lidar bem com a questão de espaço - que você precisa na direção -, com os ritmos, as pulsações, tudo isso da música e da dança, condicionada aos ritmos. Então descobri na Escola as ferramentas, o utilitário que eu precisava para tornar o sonho realidade. Eu tinha meios, a partir de então, para poder caminhar: tanto de transmitir os conhecimentos que fazem bem para o ator, como para conduzir isso no sentido da criação cênica, ou seja, das linguagens, da riqueza das linguagens. Da possibilidade, segundo o tema, de escolher uma linguagem que se adéque, ou seja, que dê maior possibilidade de transmitir isso. 


\section{Cena: E a partir daí, pode-se dizer que sempre usas esses preceitos, esses princí- pios de Lecoq?}

Maria Helena: Sim, só que eu também tenho uma aproximação muito grande com o teatro antropológico, de Eugênio Barba. As coisas compreendem dança, Lecoq, Barba, é infinito. De repente, eu faço experimentos por outro caminho. Mas eu considero que continuam sendo de formação básica esses elementos que eu adquiri na Escola, por mais que depois eles tenham tomado um outro caminho, incorporando outros conhecimentos: eles estão lá presentes sempre. Sempre que eu começo um trabalho, estou me valendo dos exercícios lecoquianos, dos princípios, de conceitos imutáveis, como quando Lecoq diz "interpretar é a modificação da matéria". Para mim isso é claro, absolutamente claro: se você não transforma a matéria não tem como, não acontece. E são as grandes formas de teatro que a gente vê embrionariamente. No meu trabalho, a improvisação está sempre ligada à dramaturgia. Das improvisações, como é que você transforma isso em dramaturgia textual. Nos Reis vagabundos, por exemplo, não tinha a dramaturgia do texto, eu tinha a composição do espetáculo pelas ações dos clowns, mas eu não tinha nenhuma palavra. Foi uma escolha: não ter palavras foi uma escolha desde o primeiro momento.

\section{Cena: Tens outros trabalhos com texto, pós-Lecoq?}

Maria Helena: Sim, a Crônica, que é o espetáculo 2. Ele tem uma linguagem realista, mas está todo embasado pelos conhecimentos lecoquianos. Desde a formação dos atores. Eu trabaIhei a partir do livro de Garcia Marques, mas não usei uma única palavra dos diálogos do livro, ou seja, trabalhei improvisação verbal. Eu acho que existe muita confusão em cima de como fazer o texto quando se trabalha com improvisação. Então, meu trabalho é o de nutrir o ator. É um trabalho infernal, eu trabalho como uma louca desatinada, para ele dizer o que eu preciso que ele diga. Raramente eu coloco uma palavra na boca do ator. Eu trabalho de tal modo que o diálogo tem que surgir perfeito, como a ação. Imagina que não é nada fácil.(risos)

\section{Cena: Sim, uma das críticas sobre o teatro de improvisação é justamente sobre a superficialidade do texto...}

Maria Helena: Exatamente! Mas uma coisa que Lecoq dizia que ficou na minha cabeça era assim: "a improvisação te oferece uma matéria primeira". Falava-se muito, na Escola, na questão da matéria primeira, ou seja, do primeiro resultado, que muitas vezes é perfeito, e muitas vezes não! Ele traz um embrião que você precisa trabalhar e re-trabalhar até a loucura! Bem, sobre o texto, é um trabalho em que todo ele é registrado a cada ensaio. $O$ escriba me entrega esse material registrado e eu reexamino e vou burilando-o. Trabalhar e re-trabalhar a partir do que eu preciso como ideia e como resultado, o mais próximo possível da "palavra justa" e da profundidade. Para mim, tenho muito presente a questão literária, do que é literário e do que é dramático. Desde sempre, fui uma criança que lia desvairadamente. Então incorporei o gosto pela linguagem e tenho um apuro auditivo muito grande. No teatro, sobretudo, me irrita tudo que for excessivo, explicativo, redundante. Eu gosto da economia, eu gosto que a palavra tenha o seu valor, seu peso. E eu acho que na escola isso também era muito trabalhado, você só abria sua boca se você realmente tinha alguma coisa muito importante para dizer, senão, cala a tua boca! (risos) Em cena e fora de cena. Então a palavra é muito importante. E é uma coisa que fica tão flagrante. Por exemplo, eu vejo alguns textos dramatúrgicos, alguns autores que me dão seus textos, eu fico lendo e, quase sem querer, leio com um lapisinho na mão e vou riscando 
o que é excessivo, expurgando o texto, mexendo no trabalho dos outros. "Porque que ela não escreve?" (risos) Mas escrever com o ator é maravilhoso, é vivo, orgânico.

\section{Cena: E você sente que a partir dali todos os seus espetáculos passaram por este processo de improvisação como na escola?}

Maria Helena: Não, nunca é o mesmo, ele sempre difere um pouquinho. Mas ainda assim, os atores têm o seu treinamento corporal o tempo inteiro, que é bastante rigoroso: trabalho de limpeza, de tirar os vícios, os estereótipos que vão ficando, as facilidades - que é outra coisa super importante a ser combatida, a saída fácil -, e a improvisação. Sempre. Não consigo imaginar trabalhar se não for pelo caminho da improvisação. E algumas vezes não passa pela personagem, veja bem, não compõe personagem. Componho personas que adquirem contorno de personagem, mas que passam por uma outra via. Mas quando são personagens, é o mesmo processo. Na "Crônica...", nós fomos todos para uma cidade pequena para que todos tivessem a mesma ideia da mesma cidade. Eu trabalhei oito meses na "Crônica...", mas os personagens existiam fora da cena. Ou seja, a minha dificuldade, a partir de um momento, era de manter os personagens onde eles estavam, porque eles evoluíam! Era maravilhoso! E isto volta a acontecer nos outros trabalhos com personagens, eles adquirem vida, pois têm uma referência na realidade.

\section{Cena: E a máscara neutra, como você usa? Qual a sua relevância?}

Maria Helena: Acho muito importante. Uso menos do que deveria, porque não tenho boas máscaras. As vezes uso o neutro sem a máscara, porque é extremamente importante nesse processo de remeter o ator a uma outra linguagem, a uma outra percepção de tempo, de realidade, de estados internos, nessa coisa da identificação, de não emprestar coisas, de não carregar nada, e de estar ativo, vivo. Essa confusão de neutro ser passivo... Meu problema agora é conseguir boas máscaras.

\section{Cena: Como você vê a relação autor $x$ improvisação?}

Maria Helena: O autor me tolhe porque eu tenho que levá-lo em consideração. E eu gosto de fazer o que está na minha cabeça, a minha loucura. Se a loucura é profunda, eu acredito nela. Ela não é fabricada, ela é legítima, eu respondo por ela. E aí eu tenho que abrir espaço para o autor, não posso ignorá-lo, desrespeitá-lo. Mas quando comecei a trabalhar "Caldweig", ignorei. Peguei o texto, que me apresentava situações maravilhosas do contexto, e resultou uma coisa maravilhosa. Daí resolvi apelar para o meu senso crítico, para o bom senso, todas essas coisas calhordas(risos), e resolvi voltar atrás e fazer o texto. Eu trabalho com a experimentação. Eu dei uma palestra em Belo Horizonte, e uma pessoa da platéia perguntou porque teatro de experimentação e não experimental? Porque me dá esse sentido de continuidade. Não é uma coisa que foi experimentada uma vez, ela é, em si, um teatro de experimentação. Porque eu acho que o teatro é riquíssimo, ele é vasto, ele é rico. E na escola do Lecoq, eu tive bem essa dimensão, da infinita riqueza, das grandes formas. Eu fui ao Japão, vi de perto o Nô e o Kabuki, e essas experiências foram muito marcantes, então eu não posso fazer teatro sempre do mesmo jeito. Ele me oferece possibilidades de variações que vai ser sempre isso: eu quero falar de determinadas coisas, qual é a melhor maneira, qual é a melhor linguagem que vai traduzir isso? 
De que forma estética, visual, emocional? Como é que eu trato isso? E a cada vez é diferente, surge uma forma diferente. Isso é muito animador. E claro, você tem que ter presente, eu acho, o quanto você domina daquilo que quer experimentar e o quanto você que tem que experimentar para dominar aquilo. E dominar em termos, porque não se domina nada absolutamente. A arte não tem ponto de limite e nenhum artista possui a perfeição. É isso, ou seja, a eterna insatisfação com a criação: está quase bom, mas tem isso ou aquilo. E a eterna insatisfação com os atores, que a cada dia modificam o raio do teu espetáculo, da tua criação maravilhosa, que passa a ser tua e não deles, já que eles não respeitam. Então tem essa coisa da falha humana, dos limites humanos que estão sempre presentes!

\section{Cena: Como você vê a chamada "dramaturgia do ator"?}

Maria Helena: Perigoso. Acho que algumas pessoas são capazes. Conheci um ator em Barcelona que era o autor do seu próprio trabalho. Mas era esse ator, e era magnífico, não me lembro o nome dele. Me impressiona a dificuldade do ator de se ver em cena. Eu acho que o ator pode criar seu próprio texto, se bem conduzido. E eu levo uma parte nisso. É complicado, porque tem que ter o domínio da palavra, da musicalidade, do ritmo, do sentido. Porque é música, na cena tudo ganha um corpo especial, ela tem que ter sua forma. Não é nem a forma de dizer, mas o que dizer, a seleção do que dizer, e claro, como dizer. Vai ter que ter uma grande acuidade, uma percepção fantástica de todos esses elementos, ou uma grande intuição tão maravilhosa que dê conta de tudo isso, porque é difícil. Eu acho que sim, ele pode ser o criador de seu texto, mas eu discuto um pouco se ele pode sê-lo sem nenhum auxílio. Eu tenho a experiência com os meus atores de que eles sim, trouxeram os seus textos, mas eles foram muitíssimo trabalhados para chegarem nisso.

\section{Cena: E a construção dramatúrgica, como se dá?}

Maria Helena: As improvisações e a dramaturgia são concomitantes. Eu não faço as improvisações separadas da questão dramatúrgica, ou seja, eu tenho uma linha do que eu quero construir, eu tenho o espetáculo na cabeça, e vou trabalhando as etapas para chegar nesse todo, mas a totalidade já está na minha cabeça, eu sei onde eu quero chegar. Eu acho que isso é fundamental. Eu não vou primeiro improvisando para ver onde aquilo vai resultar. Eu tenho a linha dramática presente, e aí eu vou trabalhando as etapas: o que eu preciso para chegar nessa totalidade. Mas eu tenho claro onde eu quero chegar, ou seja, a ideia dramatúrgica eu tenho desde o início, e aí eu vou experimentando os "comos". Por isso é concomitante, eu vou dando para os atores os elementos que eles precisam para me devolver os aspectos que vão fazer parte dessa dramaturgia, que vão compor essa dramaturgia. Muitas vezes, como aconteceu nos "Reis Vagabundos", eu tinha primeiro o final, e tinha um miolo complicado de resolver. Tudo isso absolutamente fundamentado e sempre imbricado na questão social, tudo o que eu faço. Na questão humana, antes de mais nada, porque eu acho que nada se faz, nem o social nem nada, sem o humano. Eu trabalho essas questões: o que me inquieta na natureza humana dentro das questões sociais. São situações, temas. Trabalhei muito a questão das impossibilidades do contato, das resistências à legítima entrega, só que dificilmente eu vou trabalhar um tema como uma abstração com os atores. 


\section{Cena: Como se dá esse processo da montagem dramatúrgica?}

Maria Helena: As minhas ordens são absolutamente econômicas, isso eu aprendi na Escola também, eu passo para 0 ator apenas o essencial, nada mais, para dar inteira liberdade para ele. Meu escriba vai fazer as anotações complementares e a câmera, não passo sem o escriba: ele vai fazer as anotações e me transmitir, para que eu possa trabalhar. Tenho enorme prazer em fazer a dramaturgia. É preciso encontrar o escriba certo, porque não pode ser superficial. Não basta fazer anotação do que foi dito, o que foi feito, não é isso, para isso eu tenho o gravador. Ela tem que entender o que eu estou conceituando, o que eu estou colocando ali, e que surge do calor da criação, ou seja, eu previ isto, isto e isto, mas tem uma parte que está em branco, evidente, que é para o que vai acontecer, o que deus vai mandar, ou se baixa o duende! (risos) Tem dias que você não consegue um resultado favorável, tudo bem, faz parte, mas cuidado! Não pode ter dois dias seguidos! Mas enfim, os processos criativos andam por diversos caminhos. No primeiro ano já tinha, já apontava para isso. Nos auto-cours, em outros momentos, nos comentários que Lecoq vai fazendo ao longo dos exercícios, enfim, já está tudo ali. 